Corrigendum

\title{
Corrigendum to "Work Interruption Experienced by Nurses during Medication Administration Process and Associated Factors, Northwest Ethiopia"
}

\author{
Nursing Research and Practice, Abebaw Jember Ferede $\mathbb{D}$, and Berhanu Boru Bifftu \\ Department of Nursing, University of Gondar College of Medicine and Health Science, Gondar, Ethiopia \\ Received 23 May 2019; Accepted 26 May 2019; Published 5 September 2019 \\ Copyright (c) 2019 Nursing Research and Practice et al. This is an open access article distributed under the Creative Commons \\ Attribution License, which permits unrestricted use, distribution, and reproduction in any medium, provided the original work is \\ properly cited.
}

In the article titled "Work Interruption Experienced by Nurses during Medication Administration Process and Associated Factors, Northwest Ethiopia" [1], Dr. Abebaw Jember Ferede was missing from the authors' list. Dr. Ferede was the coadvisor of Dr. Getnet's thesis and contributed to designing, writing, and commenting on the study. The corrected authors' list is shown above. The correction was made at the request of the School of Nursing, but Dr. Getnet did not agree.

\section{References}

[1] M. A. Getnet and B. B. Bifftu, "Work interruption experienced by nurses during medication administration process and associated factors, Northwest Ethiopia," Nursing Research and Practice, vol. 2017, Article ID 8937490, 7 pages, 2017. 


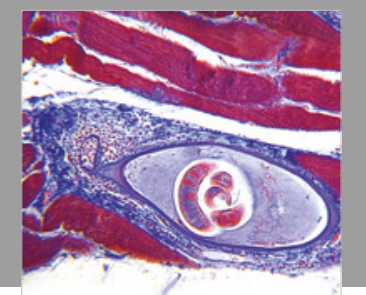

Gastroenterology Research and Practice

$$
=
$$
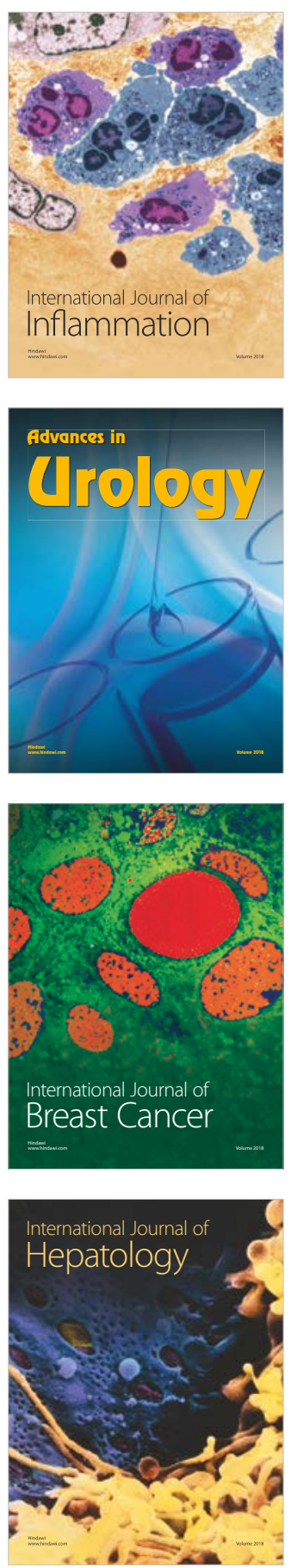

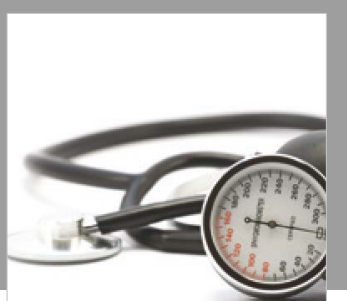

Nursing

Research and Practice

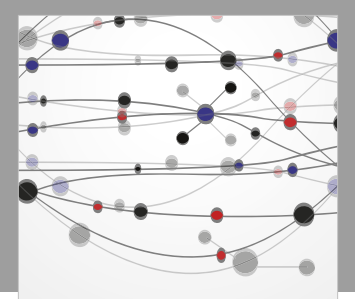

The Scientific World Journal
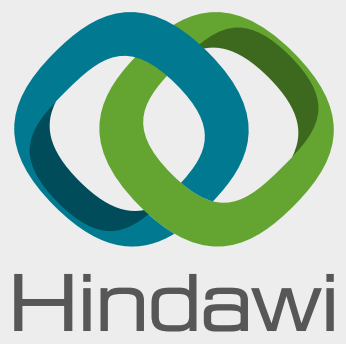

Submit your manuscripts at

www.hindawi.com
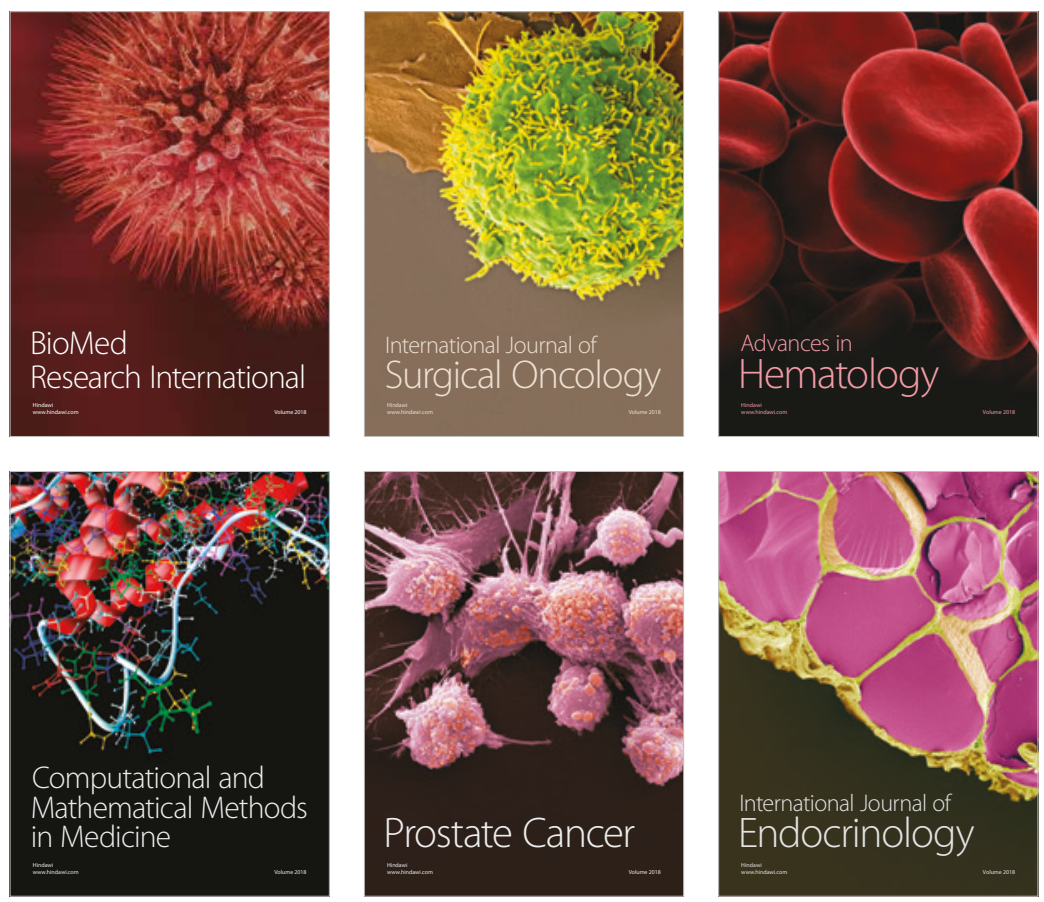

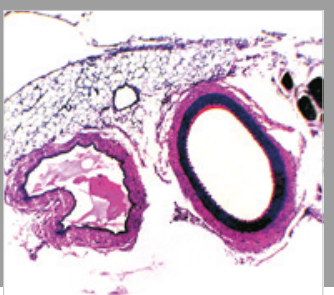

international Journal of Hypertension

Scientifica
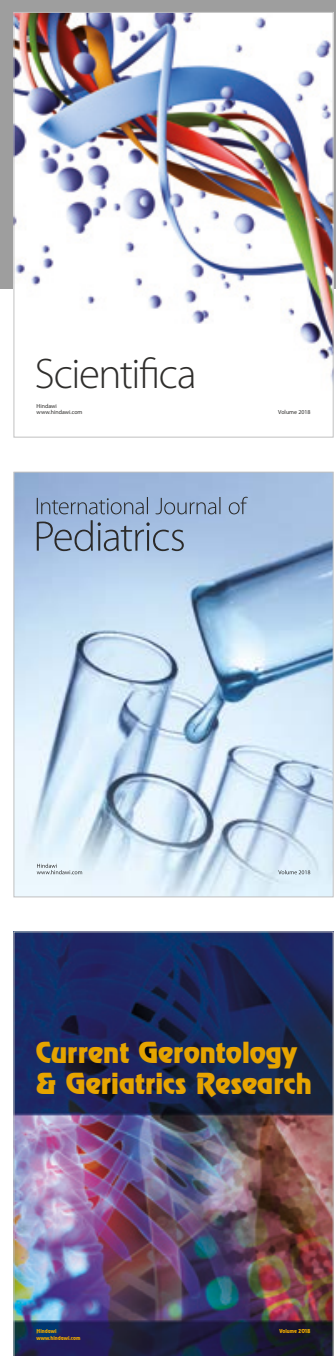

Current Gerontology \& Geriatrics Research
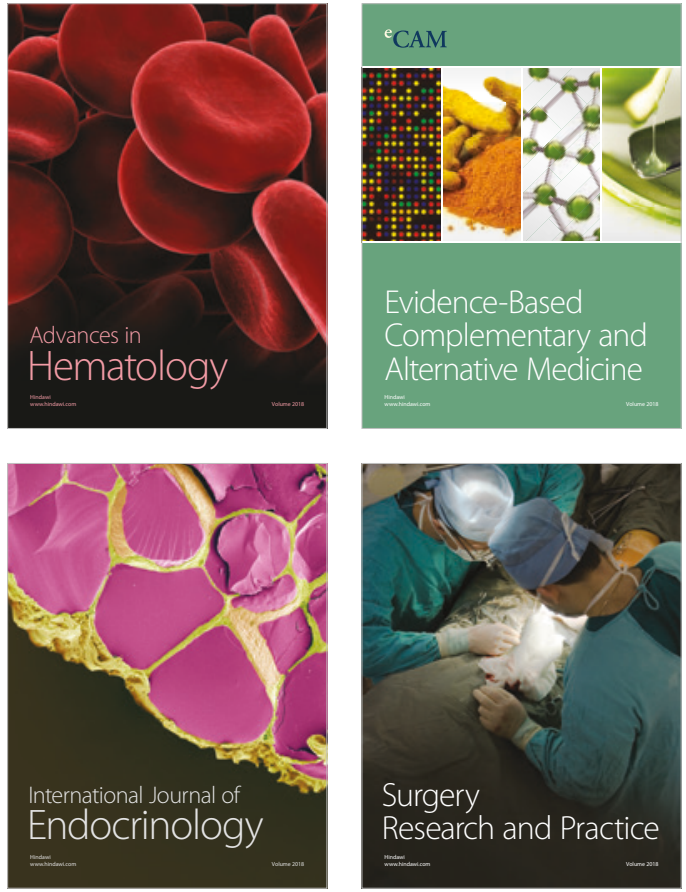